\title{
Optimization of 3D Printing Model Data of Complex Sculpture Ceramic Mold
}

\author{
Han $\mathrm{Xu}^{1}$, Zhicheng Huang ${ }^{2, *}$, Wen $\mathrm{Han}^{3}$ and Shouyi Chen ${ }^{4}$ \\ College of Mechanical and Electronic Engineering, Jingdezhen Ceramic Institute, Jiang Xi, Jingdezhen 333001, China \\ ${ }^{*}$ Corresponding author
}

\begin{abstract}
This paper mainly introduces how to deal with the point cloud data of ceramic sculpture obtained from 3D scanning, getting the data that can be read and easy to print for threedimensional printer. The paper combines the characteristics of production process of complex ceramic sculpture mold, using Geomagic and PRO/E for complex three-dimensional model data optimization and giving the model to the printer to generate NC code. As a result, achieving its rapid, efficient, low-cost printing, meeting the rapid manufacturing of the current increasingly urgent need of ceramic mold especially complex ceramic sculpture mold.
\end{abstract}

Keywords-3D scanning; 3D printing; sculpture ceramics; mold; data optimization

\section{INTRODUCTION}

At present, the number of the only remaining sculpture ceramic works with high artistic art value is limited. In order to meet the needs of the consumer market, it is necessary to copy these works of sculpture ceramics. The first step is to quickly create model species with very high degree of similarity, , and then produce gypsum working molds through the model species, Followed by printing or grouting, etc. to get sculpture ceramic bodies, and finally through a series of replication process to get sculpture ceramics. The process is shown in Figure I.

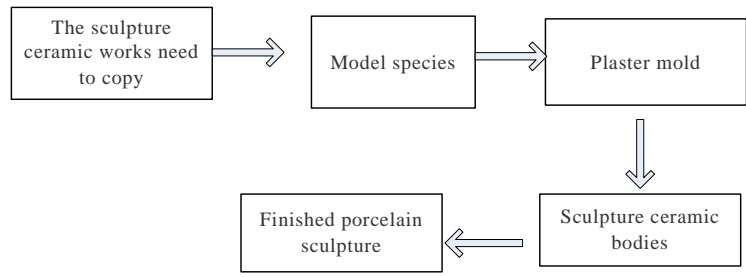

FIGURE I. PROCESS OF COPYING SCULPTURE CERAMIC

In the series of processes above, the most critical step is to produce the model species with high degree of similarity. The traditional handmade is time-consuming and the model species obtained have low similarity, and the artistic realm of the copy works is not as good as the original.

With the development and popularization of the threedimensional scanning and three-dimensional printing technology, and its application in the production of sculpture ceramics is possible.

However, due to the particularity of the ceramic technology, there are many problems in practice. Therefore, it is necessary to fully integrate the characteristics of ceramic production process to solve these problems with the use of related software.

Before printing a ceramic model, one must first obtain a three-dimensional digital model of the product and provide it to the print software for slicing to obtain the NC code for the printer to print. In this paper, the method how to reconstruct 3D point cloud data obtained by three-dimensional scanner, and optimize it with the ceramic production process so as to obtain the replicas with high similarity is introduced.

\section{APPLIED EXAMPLE}

Taking a sculptural ceramic character as an example, obtain the point cloud data of the person model by using the raster scanning system. The reverse modeling and correlation processing of the prefabricated ceramic character model before printing are completed in Geomagic Studio and Pro / e based on these data.

\section{A. Model Splicing}

As shown in FIGURE II, the saved object format file of the ceramic sculpture character model through the raster scanning system is imported into the Geomagic software. Geomagic's main feature is to support a variety of scanner file format read and conversion, massive point cloud data preprocessing[2].

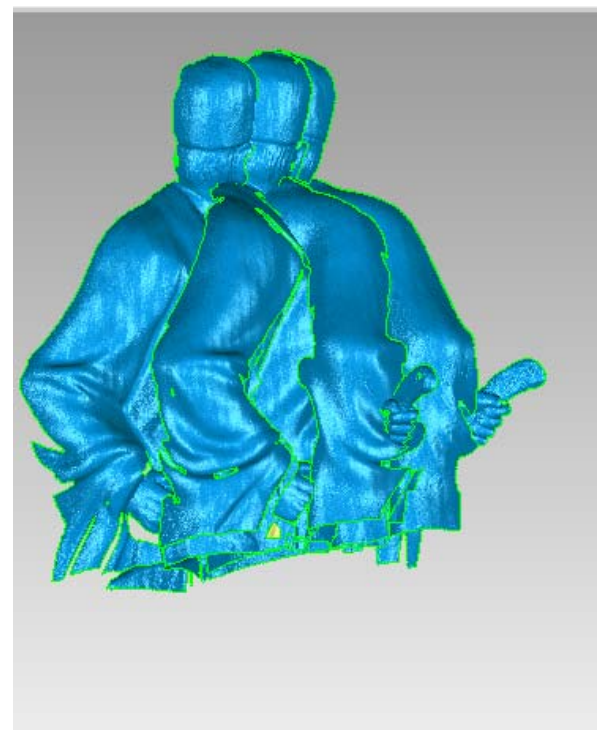

FIGURE II. SCANNING THE POINT CLOUD DATA IMPORT GEOMAGIC 
The imported point cloud in Geomagic is default 'package' state. One can first merge the model scanned at each angle, and then use the 'converted to point' function for the merged model, carry on the operations of 'disconnect component connection', 'in vitro acnode', 'reduce noise', 'unified' and so on for the point cloud, finally, encapsulate them. The final character model obtained is shown in Figure III.

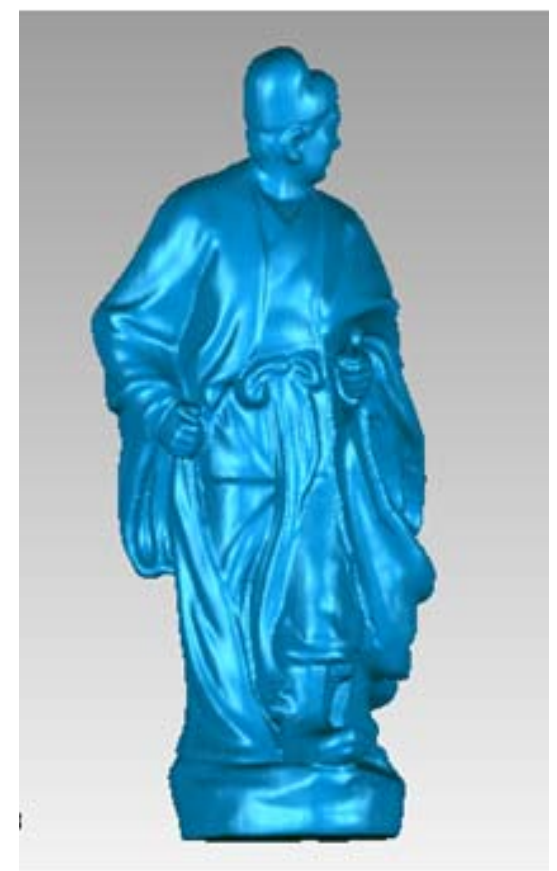

FIGURE III. SPLICING COMPLETED OF THE CHARACTER MODEL

\section{B. Model recovering}

In the scanning process, the model itself maybe shade some certain parts, furthermore, There is a gap when using software to connect point cloud at different view. Therefore, the model may be damaged or the model surface is rough after splicing. One can fill the damaged parts with the fill hole command. The effect of the model recovering is shown in Figure IV

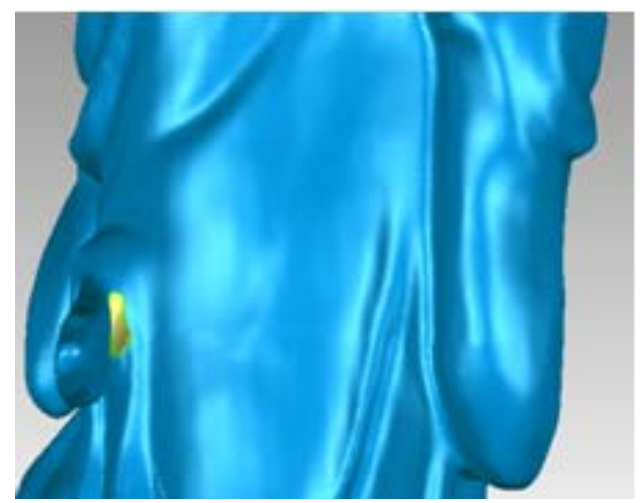

(A)

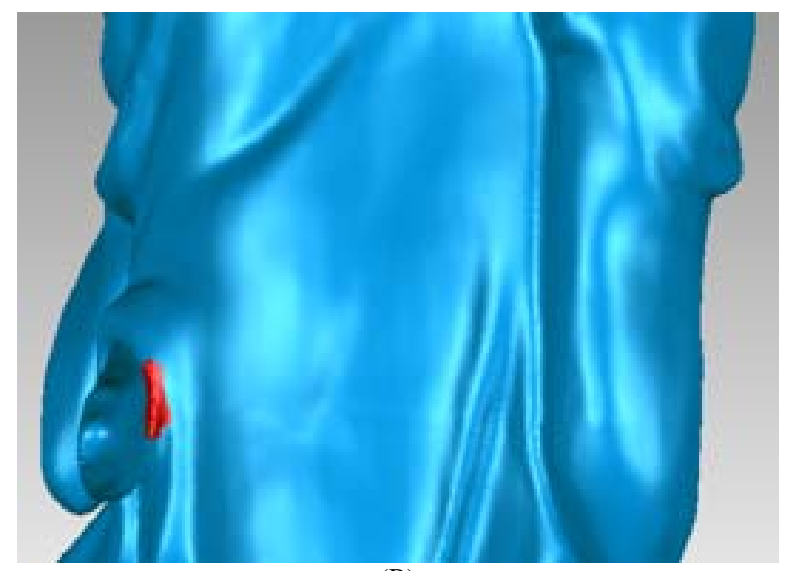

(B)

FIGURE IV. COMPARED BEFORE AND AFTER REPAIR: (A)BEFORE THE REPAIR , (B)AFTER THE REPAIR

\section{Model Zoom}

Sculpture ceramic shrinks during firing. The scanned model is often the ceramic after firing, however, the printed mold species have the shape before firing. There are different size between them. Therefore, it is necessary to further optimize the model.

Because different mud material has different shrinkage, therefore, the model zoom operation must be based on the actual situation of the mud. According to the experience of ceramic production, most of the mud is $86 \%$ shrink, plus the impact of gravity. In this study, the vertical enlargement model was used as the original $120 \%$, and the horizontal direction was enlarged to $116 \%[3]$. Figure $\mathrm{V}$ shows the result of the model zoom.

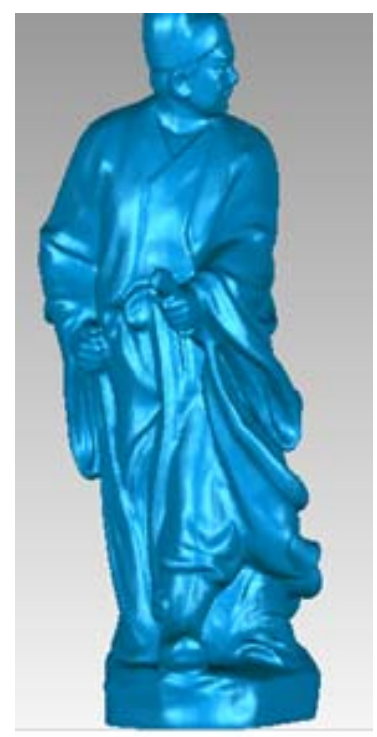

FIGURE V. TO ENLARGE THE MODEL

\section{Model Cutting}

The size of the ceramic mold to print is often greater than the printer's print space. Therefore, the next step is to try to 
split the big model into a small model to print. Using the 'cut' function of Geomagic software, the model can be divided into multi-segment, and the cutting plan is shown in Figure VI.

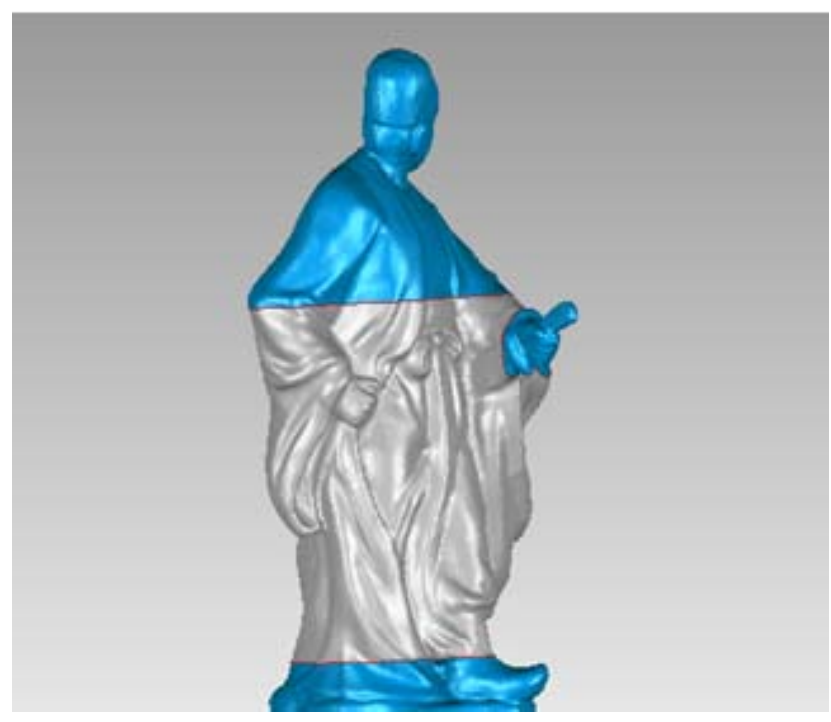

FIGURE VI. CUTTING PLAN

As long as each of the cutting parts are printed separately, and then bonded them together to get any size of the ceramic mold.

\section{E. Resetting Model Coordinates}

A real object has a position state in the real space, and the $3 \mathrm{D}$ model also has a position in the virtual 3D world. Each of the three dimensional software has an ideal 0 point position and three mutually perpendicular ideal planes. There is a certain relationship between the position of the three-dimensional model and the 0 points and the planes. In order to easier observe and for different software more compatible coordinate position of the three-dimensional model, the coordinates of the three-dimensional model need to reset. that is, placing the three-dimensional model on the three vertical plane in the software by default.

Therefore, after the character model is cut, each split part of the character model is placed on the default reference plane of the Geomagic Studio software (like the xy plane). The purpose is for the different software to be compatible with the threedimensional model coordinate position. This operation is critical to the subsequent smoothing of the 3D print starting surface with the printing platform.

Through the processing above, the space position of the model is optimized, which will help layers of the materials stack during printing, and reduce or even remove the printed support material.

\section{F. Further Processing in Pro / e}

In order to further reduce the amount of material required to print the model, a simple way is as possible to remove the internal print material while ensuring the strength of the mold at the same time. The PRO / E software is used to deal with this here.
Take the foot model as an example. The foot model is imported into the PRO / E to remove the internal materials, and the method is to use the 'mixed' removal material in PRO / E. When using this method, the 'section' should be as similar as possible to the model. The results of removing the internal material are shown in Figure VII

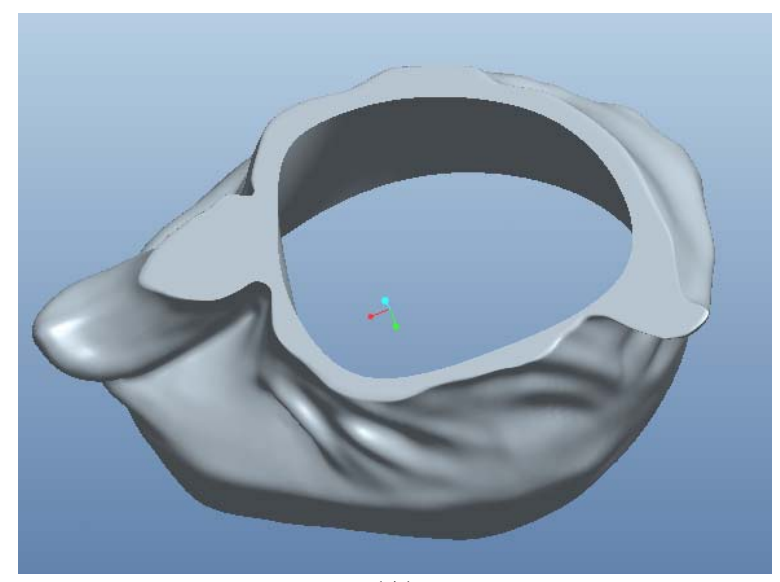

(A)

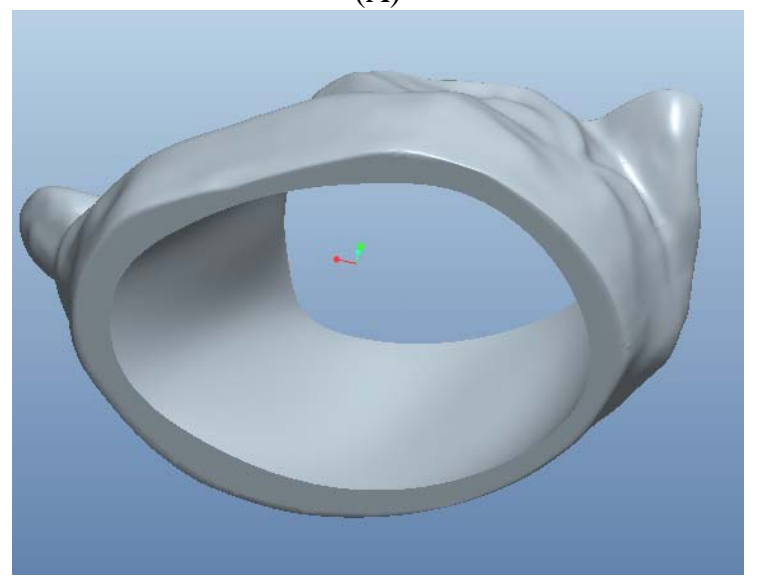

(B)

FIGURE VII. THE RESULT OF REMOVING INTERNAL: (A) SEEING MODEL FROM ABOVE, (B) SEEING MODEL FROM BELOW

After the processing above, the purpose of trying to remove the internal filling has achieved, and the amount of material in the model are reduced. The following step is to export the STL format of the model, and then import the model file with STL format into the three-dimensional printing software, carry on the slice processing and then export the relevant NC program, one can achieve the rapid print molding of the mold.

\section{CONCLUSIONS}

Based on the research of sculpture ceramic production technology, this paper applies three-dimensional scanning and three-dimensional printing technology to the production of complex sculpture ceramics, solves some problems encountered in the process of model processing, and realizes the printing molding of the complex sculpture ceramic mold with precision, high efficiency and low-cost. It has important application value in the sculpture ceramic industry and antique sculpture ceramic field. 


\section{ACKNOWLEDGMENT}

This research is funded by the China Jiangxi Provincial Department of Education Program (JXJG-16-11-1) and Jingdezhen Ceramic University Doctor Research Program 'Study on Vibration Reduction Performance of Passive Constrained Damping Structures', and the authors are grateful to them for supporting the research.

\section{REFERENCES}

[1] Yongqin Ji, Wen Han. Ceramic mold CAD / CAM system[J]. Journal of Jingdezhen College.,2010, (2):23-24

[2] Yingfeng Hu. Application of Geomagic Studio Software in Reverse Engineering Postprocessing [J]. Journal of Manufacturing automation.2009,(9):135 -137

[3] Tiecheng Ma. Ceramic Technology [M].Beijing: China Light Industry Press, 2013.1

[4] Wen Han, Yutao Wang, Han Xu. Application of 3D Scanning Technology in Shaped and Ultra - thin Ceramic Carving [J]. Journal of Ceramics, 2014, (3):314-317

[5] Wenguang Liu, Yusheng Shi, Kai Liu, Jinghua Feng, Jia Xu. Study on Artificial Ceramic Forming Method Based on Selective Laser Sintering Technology [J]. Journal of Ceramics, 2014, (4):426-428

[6] Han $\mathrm{Xu}$, Wen Han, Naxing Wu. Study on Rapid Prototyping System of Ceramic Gypsum Mold [J]. Journal of Ceramics, 2010, (4):607-610

[7] Xi Chen. Surface Fitting and Model Accuracy Analysis Based on Reverse Engineering [D].Hefei:Hefei University of Technology, 2012

[8] Jiahua Zhang, Zhixiang Chen, Lianqiang Xu, Jianqing Ren. Production Method of Zisha Teapot Mold Based on Reverse Engineering [J]. ceramics, 2010, (12):32-34 